\title{
Feasibility of Regenerative Suspension System
}

\author{
Shreyas Honagekar ${ }^{1}$, Rajat Gawas ${ }^{2}$, Aniruddha Joshi $^{3}$, Aniket Bharambe ${ }^{4}$ \\ ${ }^{1,2,}$ (Department of Mechanical Engineering, Suman Ramesh Tulsiani Technical Campus Faculty of Engineering, \\ Kamshet, Pune, University of Pune, India) \\ ${ }^{3,4}$ (Department of Mechanical Engineering, Dr. D. Y. Patil College of Engineering, Akurdi, Pune, University of
} Pune, India)

\begin{abstract}
With the increasing number of vehicle possession and severe hike in consumption natural fuels which are obviously limited and on the verge of extinction, the area of energy conservation and saving have received great attention from automobile manufacturers and the government all over the world. Usually the vibration energy caused by road roughness when the runs have not being paid attention to and it is wasted through conversion to thermal energy. If the vibration energy can be recovered and converted to other form of energy so as to supply for other devices then the aim of eco-friendly energy saving is reached.This report consists of design, analysis and manufacturing of mechanical regenerative shock absorber in detail. The mechanism of this innovative shock absorber implies use of a simple D.C generator for the conversion of energy possessed by the relative motion between vehicle wheels and the chases. At the same time, the damping can remove the discomfort caused by the irregular road surface. The regenerated electric power can be recovered through the battery. The analysis of gears used in the system for lower inertia and better performance was performed on the software based on the structure parameters as found by the design calculations. Analysis and calculations prove the viability of this shock absorber.
\end{abstract}

Keywords: Regenerative Suspension System, Rack and Pinion Assembly, SHM, SolidWorks

\section{Introduction}

Energy crisis and environmental problems such as oil shortage and atmospheric pollution have brought challenges for new development of an energy saving, efficient and environmentally friendly power transmission system in vehicles. In recent years, electric vehicles play a major role in attaining sustainability and reducing air pollution. The current status of EV (electric vehicle) developments is encouraging. Several countries worldwide have ambitions to electrify their car fleet. EVs have an advantage over conventional internal combustion engine automobiles since they do not emit harmful tail pipe pollutants from the on board source of power. However, there still remain many challenges and unsolved issues in the development of EVs. The price of EVs is significantly higher than traditional vehicles, even after considering government incentives for EVs available in several countries. The primary reason for high prices is the high cost of vehicle batteries. In addition, the efficiency of EVs is low because they have a short driving range and a long charging time. Electricity consumption for air conditioning or cabin heating can also shorten the driving range in areas with hot/cold weather. Due to the unsolved problems, research efforts turn to developments of energy harvesting from the vehicle kinetic energy as a new driving source to increase the efficiency of vehicles and decrease their costs. In fact, only a small part of energy from the on board source of vehicles is used for driving, while most of the energy dissipating during vibrations and motions. If vibrations of vehicles can be absorbed and reused fully, the utilization efficiency of on board source could be improved notably. Research efforts on energy recovery from vehicle suspensions, first as an auxiliary power source for active suspension control, and later as energy regenerating devices in their own accord, have been developed during recent years. Previous studies on regenerative vibration absorbers of vehicles were all designed to generate electric energy from vibrations of vehicles by electromagnetic materials. These absorbers were fixed in parallel with a suspension spring which indispensably dissipates a part of vehicle vibration energy, and hence cannot fully absorb and transfer the kinetic energy from the suspension system. In addition, the conversion efficiency of electromagnetic materials is not very high. Currently, the mostly available vibration-to-electric conversion mechanisms are electromagnetic, electrostatic, and piezoelectric transductions.

Vehicles are widely used all around the world and cause a lot of energy and environmental issues. The primary function of vehicle suspension is to reduce the vibration disturbance from road roughness, acceleration, deceleration, and cornering to the chassis for better ride comfort, and to maintain good tire-ground contact force for better vehicle handling and mobility. Traditional suspension systems consist of springs and viscous shock absorbers. Hydraulic shock absorbers dissipate the vibration energy into waste heat to ensure the ride comfort and road handling. Due to the simplicity and reliability, passive dampers are favored and used in almost all vehicles nowadays. Generally speaking, softer dampers provide more comfortable ride, while stiffer ones provide better stability and thus better road-handling.There is a very specific \& precise scope for increasing the 
average. But there is a wide scope for regeneration of energy like regeneration of breaking system etc. We have decided to work on utilization of suspending mass of a vehicle through regeneration system with the help of shock absorber. Shock absorbers are having reciprocating motion in it.

By newly designed suspension regeneration system presently using alternator is detached from the engine and attached to the suspension system. If we install this regeneration system for all 4 wheels then we can generate high amount of electric power. This high amount of electric power can be used for the working of car air conditioner or refrigeration system of vehicles. This suspension system will be mostly useful for heavy compressed vehicles, milk trucks, fire brigade trucks and also those having high requirement of electricity inside it. We propose a design plan that converts the mechanical energy in cars to electrical energy much more efficiently than it has been done before. The electricity generated will then be used to recharge the car battery for further use for functioning of the car.

\section{Problem Definition}

The internal combustion engine used in current automobiles has efficiency of around $30 \%$ to $40 \%$. From this small efficiency, apart from generating tractive effort for vehicle movement the engine has to run various systems such as lighting system, air conditioning system, ECU of vehicle, etc. The alternator used to charge battery is directly coupled to engine shaft. As a result of it, the alternators directly or indirectly consume brake power obtained at engine shaft with very low efficiency. The amount of energy consumed by the alternator is approximately $4 \%$ of total energy generated. So this creates a situation for us where need to replace the alternator to some system which will not add up to the engine load and also recover the waste energy which is dissipated to the surrounding. As per research, we could find two such systems which have high energy potential and is not being utilized i.e. brake power and suspension power. Suspension system seem to be more promising so we decided to develop a system which regenerates the energy obtained from the continuous displacement of suspension system. If we couple this system to all four wheels of vehicle, it can fulfil the demand of charging battery. This electricity can later be supplied to other systems.Currently there is suspension energy regenerating system which works on principles such as hydraulic system, electromagnetic system, pneumatic system, piezoelectric system, etc. But the drawback of these systems is complex construction, difficult to maintain, high cost, less reliability.

\section{Mechanical Regenerative Suspension System}

Mechanical Regenerative system consists of a rack and pinion assembly which will convert the linear motion of wheel to rotary motion. This rotating motion of pinion is then coupled to a reduction gearbox which will increase the angular velocity at output. This high rpm output is then connected to a DC Generator. Regenerative shock absorbers have potential not only to harvest the kinetic energy traditionally wasted in suspension vibration, but also to be used as actuators for suspension control. Moreover, it can increase the fuel efficiency by reducing the electrical demand to the car alternators and thus reduce engine's work load.

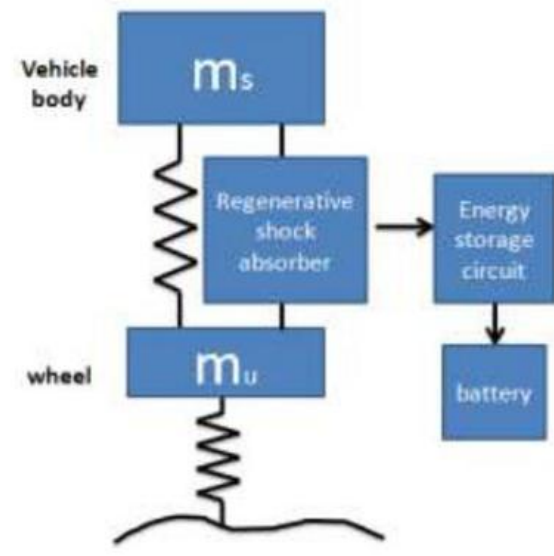

Figure 1. Block Diagram of Regenerative Suspension System

\section{Rack and Pinion Assembly}

A rack and pinion mechanism is used to transform rotary motion into linear motion and vice versa. A round spur gear, the pinion, meshes with a spur gear which has teeth set in a straight line, the rack. Itis a type of linear actuator that comprises a pair of gears which convert rotational motion into linear motion. A circular gear called "the pinion" engages teeth on a linear "gear" bar called "the rack"; rotational motion applied to the pinion causes the rack to move, thereby translating the rotational motion of the pinion into the linear motion of the rack.A round spur gear, the pinion, meshes with a spur gear which has teeth set in a straight line, the rack and 
pinion is a type of linear actuator that comprises a pair of gears which convert rotational motion into linear motion. A circular gear called "the pinion" engages teeth on a linear "gear" bar called "the rack"; rotational motion applied to the pinion causes the rack to move, thereby translating the rotational motion of the pinion into the linear motion of the rack. For example, in a rack railway, the rotation of a pinion mounted on a locomotive or a railcar engages a rack between the rails and pulls a train along a steep slope.

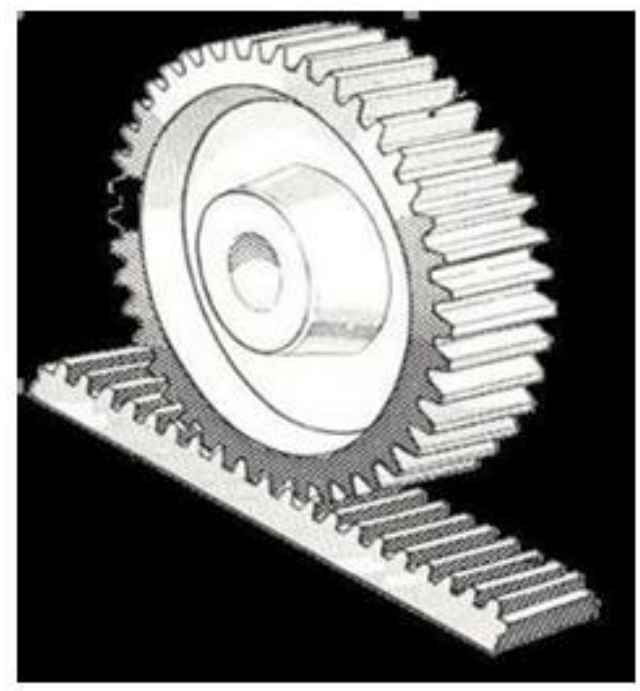

Figure 2. Rack and Pinion Assembly

\section{Design}

\subsection{Force Calculations:[2]}

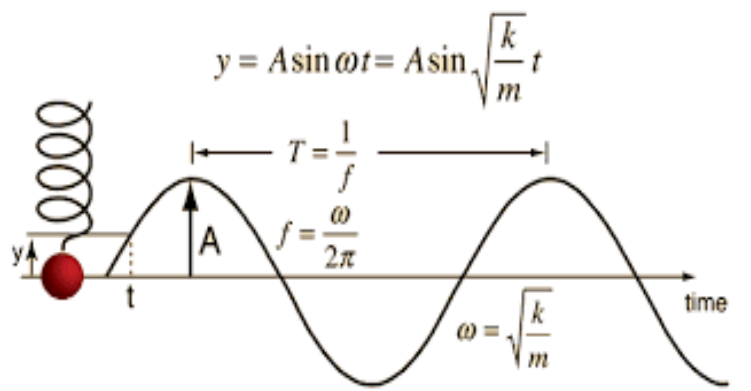

Figure 3. Simple Harmonic Motion

In shock Absorber the arrangement is of spring mass damper system, which follow the simple harmonic motion for its linear vibration.

The displacement function $\mathrm{x}$ can be given as,

$$
x=A \sin 2 \pi \frac{t}{\tau}
$$

Where $\tau$ is periodic motion which is nothing but time interval with which the cycle repeated Itself. In SHM the cycle is repeated with each phase angle of 180 degrees.

$$
\tau=\mathbf{2} \pi=180 \text { degrees. PhaseAngle }
$$

For the given shock absorber system of Maruti Suzuki Alto 800, the maximum shock length is 3inch which gives the displacement of $76.2 \mathrm{~mm}$. So in given shock absorber system the value of A i.e. Amplitude of vibration $=76.2 \mathrm{~mm}$.

The displacement function $\mathrm{x}$ can also be given by

$\boldsymbol{x}=\boldsymbol{A} \sin \omega \mathrm{t}$.

Phase $\omega$ is given by,

$\boldsymbol{\omega}=\frac{2 \pi}{\tau}=\frac{2 \pi \times 180}{180}=2$. Therefore $\omega=2$.

Also in equation $x=A \sin \omega t$,

$\mathrm{t}$ is maximum time travel of maximum amplitude i.e. distancetravel $=$ shock absorber can be calculated. 
which is given by,

$$
V=\sqrt{5.4 D \sin (A)}
$$

where $\mathrm{D}=$ distance moved by weight and $\mathrm{A}=$ Angle of inclined plane

$V=\sqrt{5.4 \times 3^{\prime \prime} \times \sin (90)}=4.02 \mathrm{feet} / \mathrm{sec}$.

$\mathrm{V}=1.22 \mathrm{~m} / \mathrm{sec}$

Now the time constant of given shock absorber stroke of 3 inch. We know that

$t=\frac{76.2}{1000 \times 1.22}=0.0624 \mathrm{sec}$

$$
v=\frac{\text { distance }}{\text { time }}
$$

The first order displacement of time function is given by,

$$
\begin{gathered}
x=A \sin \omega t \\
\boldsymbol{x}=\mathbf{1 . 6 5 9 7} \times 10^{-4}
\end{gathered}
$$

Similarly the second order displacement of time function is given by,

$$
\begin{gathered}
\dot{x}=\omega A \sin [\omega t+\pi / 2] \\
\dot{\boldsymbol{x}}=\mathbf{1 . 3 8 7 6} \\
\ddot{x}=\omega^{2} A \sin (\omega t+\pi) \\
\ddot{\boldsymbol{x}}=\mathbf{0 . 0 1 7 3}
\end{gathered}
$$

Also,

The force equation for simple degree of freedom is given by,

where $\mathrm{m}$ is static mass on body.

$$
\boldsymbol{F}=\boldsymbol{m} \ddot{x}+c \dot{x}+k x
$$

In proposed mechanism the static mass is given by,

$\mathrm{m}=$ Mass of body + Average passenger weight

mass of body $=695 \mathrm{~kg}$

Average passenger weight $=5 \times 60=300 \mathrm{~kg}$

Total static mass $=695+300=995 \mathrm{~kg}$

Mass on each wheel $=248.75=250 \mathrm{~kg}$

Stiffness K can be calculated as follows,

$$
\begin{gathered}
K=\frac{F}{d} \\
=\frac{(6920 \times 0.45)}{(2.91 \times 25.4)} \\
K=42.13 \mathbf{N} / \mathbf{m m}
\end{gathered}
$$

The value of damping factor $\mathrm{c}$ can be calculated by,

$\alpha=0.5$

$$
c=\alpha(\mathrm{M})+\beta(\mathrm{K})
$$

$\beta=30 \times 3.14$

$\mathrm{M}=250$

$\mathrm{K}=42.13 \mathrm{~N} / \mathrm{mm}$

Therefore, $\mathrm{c}=0.5(250)+30 \times 3.14(42.13)$

$\mathrm{c}=4093.646$

The force equation for single degree of freedom system is given by,

Substituting the above values in the force equation,

$$
F=m \ddot{x}+c \dot{x}+k x
$$

$\mathrm{F}=250(0.0173)+4093.646(1.3867)+42.13\left[1.6597 \times 10^{-4}\right]=5680.99$

$\mathrm{F}=\mathbf{5 6 8 0 . 9 9}$

4.2 Design of Spur Gear [1]

As per the approach towards Selection Design and space constraint , the value of module is selected as $2.5 \mathrm{~mm}$ For $20^{\circ}$ full depth system, $\alpha=20^{\circ}$

Minimum number of teeth on pinion can be calculated as,

$$
\begin{gathered}
Z \min =\frac{2}{\sin ^{2} \alpha} \\
Z \boldsymbol{m i n}=\mathbf{1 7}
\end{gathered}
$$

With the reference of Force Calculations, $V=1.22 \mathrm{~m} / \mathrm{s}$. Therefore,

$$
\begin{aligned}
& V=\frac{\pi D N}{60 \times 1000} \\
& =\frac{\pi \times m \times z \times N}{60 \times 1000}
\end{aligned}
$$


where $\mathrm{m}=$ module $=2.5 \mathrm{~mm}$

$$
1.22=\frac{\pi \times 2.5 \times 17 \times N}{60 \times 1000}
$$

Number of teeth on pinion $\mathrm{z}=17$.

Therefore, $\mathrm{N}=548$ RPM.

As per the generator specifications the range of speed of the generator is about 60 RPM. Therefore,

Gear Ratio, G = Input Speed / Output Speed

$$
=548 / 60
$$

$$
\mathrm{G}=9.13
$$

Depending upon the value of Gear Ratio, Two stage Gear Box is selected.

Now, the gear ratio in each stage can be calculated as, $g=\sqrt[n]{G}$

Where, $\mathrm{n}=$ no of stages.

$g=\sqrt[2]{9.13}=3.02=3.0$ (approx)

Therefore the gear ratio in each stage is 3.0

Checking for number of teeth on gear and pinion,

Minimum number of teeth on pinion $\times$ Gear ratio in each stage.

$17 \times 3.0=51$.

As the output value is not in fraction, therefore the values of number of teeth on pinion and gear can be selected as $\mathrm{Zp}=17$ and $\mathrm{Zg}=51$.

The Effective Load on Gear Tooth s given as,

Where $\mathrm{Ks}$ is the Service factor, $\mathrm{Ks}=1.25$

$$
P e f f=\frac{K s \times K m \times P t}{K v}
$$

$$
\mathrm{Km}=1.0
$$

For ordinary cut gears made with form cutters and $\mathrm{v}<10 \mathrm{~m} / \mathrm{s}$, the value of Velocity factor, $\mathrm{Kv}=\frac{3}{3+v}$.

$K v=\frac{3}{3+1.22}=0.7109$.

With the reference of Force Calculations the Tangential Force on gear tooth is given by, $\mathrm{Pt}=5680.99 \mathrm{~N}$.

Now, substituting the values in the equation of effective load,

The effective load on gear tooth is $9989.08 \mathrm{~N}$

$$
\text { Peff }=\frac{1.25 \times 1.0 \times 5680.99}{0.7109}=9989.08 \mathrm{~N}
$$

Beam Strength of gear tooth (LewisEquation) is given by,

$$
S b=m \times b \times \sigma b \times Y
$$

In order to avoid the breakage of gear tooth due to bending, the beam strength should be more than the effective force between the meshing teeth. Therefore,

$9989.08=2.5 \times 2.5 \times 10 \times \sigma b \times 0.302$

$$
S b \geq \operatorname{Peff}
$$

$\sigma \mathrm{b}=529.227 \mathrm{~N}$

Substituting the value of $\sigma \mathrm{b}$ in the equation and calculating the beam strength.

$$
S b=2.5 \times 10 \times 2.5 \times 529.227 \times 0.302=9989.02 \mathrm{~N}
$$

The beam strength is $9989.02 \mathrm{~N}$.

Wear Strength of gear tooth by Buckingham's equation is given by,

$$
\begin{aligned}
Q & =\frac{2 z g}{z g+z p} \\
& =2(51) /(17+51) \\
Q & =1.5 \\
\mathrm{dp} & =\mathrm{m} \times \mathrm{zp}=42.5
\end{aligned}
$$$$
S w=b \times d p \times Q \times K
$$

Substituting the values in the equation of wear strength and calculating the value of load - stress factor (K),

$9989.08=2.5 \times 10 \times 1.5 \times 17 \times 2.5 \times K$

$\mathrm{K}=6.26 \mathrm{MPa}$.

The load - stress factor $(\mathrm{K})$ is given by, 


$$
K=0.16\left[\frac{B H N}{100}\right]^{2}
$$

Substituting the value of load - stress factor in the above equation and calculating the value of surface hardness of gears (Brinell hardness number).

$$
\begin{gathered}
6.26=0.16\left[\frac{B H N}{100}\right]^{2} \\
\boldsymbol{B H N}=\mathbf{6 2 6}
\end{gathered}
$$

Hence, depending upon the value of surface hardness of the gears, $40 \mathrm{C} 8$ with $0.20 \%$ Carbon Steel material is selected for Spur Gears.

\subsection{Design of Shaft: [1]}

Among all the shafts present in the gearbox, the maximum load is acting on the intermediate shaft. Therefore Shaft 2 should be designed.

Diameter of shaft can be calculated with relation

Now $\tau_{\max }=$ maximum shear stress $(\mathrm{MPa})$

$$
M e=\frac{\pi}{16} \times d^{3} \times \tau
$$

Shaft material is taken as $\mathrm{C} 40$

With the reference of Design of Machine Elements by Bhandari the values of $\mathrm{Kb}$ and $\mathrm{Kt}$ are taken as 1.5 and 1.0 respectively.

Tensile Strength $\left(\mathrm{S}_{\mathrm{ut}}\right)=650 \mathrm{MPa}$

Yield strength $\left(\mathrm{S}_{\mathrm{yt}}\right)=350 \mathrm{MPa}$.

Now, applying the relation for selecting the value of $\tau_{\max }$,

$\tau_{\max }=0.30 \times 350=105 \mathrm{MPa}$

$\tau_{\max }=0.18 \times 650=117 \mathrm{MPa}$

Selecting the lower value, i.e. $\tau_{\max }=105 \mathrm{MPa}$.

For calculating the diameter, equivalent bending moment i.e. should be calculated, and it is given as follow:

Where $\mathrm{T}=$ Torque acting on the shaft and

$$
M e=\sqrt{\left[(K m \times M)^{2}+(K t \times T)^{2}\right]}
$$

$\mathrm{M}=$ Moment acting on the shaft.

Torque (T) can be calculated as follows,

$$
P=\frac{2 \pi N T}{60 \times 1000}
$$

Now for calculating Torque from the above relation we need to calculate Power. Therefore Power $(\mathrm{P})$ can be calculated with the relation of tangential load which is given by,

$$
P t=\frac{P}{V}
$$

Where Pt is the tangential load and V is the velocity. With the reference of Force Calculations the values of Pt and $\mathrm{V}$ are $\mathbf{5 6 8 0 . 9 9} \mathrm{N}$ and $\mathbf{1 . 2 2} \mathrm{m} / \mathrm{s}$ respectively.

Now substituting the above values in the above quation and calculating the value of Power.

$$
\begin{aligned}
\mathrm{P} & =\mathrm{Pt} \times \mathrm{V} \\
& =5680.99 \times 1.22 \\
& =6930 \mathrm{~W}
\end{aligned}
$$

Therefore $\mathbf{P}=\mathbf{6 . 9 3} \mathbf{k W}$.

Now substituting the value of $\mathrm{P}$ in the equation of Power and calculating Torque.

Therefore Torque (T) is $\mathbf{1 2 0 . 7 6} \mathbf{~ N m}$.

$$
6.93=\frac{2 \pi \times 548 \times T}{60 \times 1000}
$$

Now Moment can be calculated with the following relation,

$$
M=\sqrt{\left[(M H)^{2}+(M V)^{2}\right]}
$$

For calculating the values of $(\mathrm{MH})$ and $(\mathrm{MV})$, the values of length of shaft is required which is unknown. Therefore the length of shaft can be calculated as follows:

Calculating the distance from the bearing to the primary force acting on the intermediate shaft. i.e. L1.

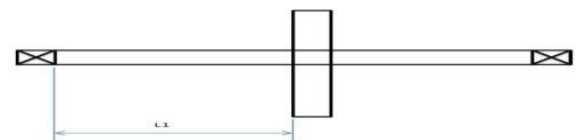

Figure 4. Length of shaft 
1) Width of gear, $b=10 \mathrm{~m}=10 \times 2.5=25 / 2=12.5 \mathrm{~mm}$.

2) Distance between casing and rotating parts $=15 \mathrm{~mm}$.

3) Thickness of wall $=0.025 \mathrm{a}+5$ where $\mathrm{a}$ is the centre distance which is given by, $\mathrm{a}=\mathrm{m}(\mathrm{zp}+\mathrm{zg}) / 2=85$. Thickness $\mathrm{t}=7.125 \approx 8 \mathrm{~mm}$.

4) Clearance between wall and bearing $=15 \mathrm{~mm}$.

Therefore $\mathrm{L} 1=1+2+3+4=12.5+15+8+15, \mathbf{L} \mathbf{1}=\mathbf{5 0 . 5} \mathbf{~ m m}$.

Similarly calculating the distance between the two forces acting on the intermediate shaft (L2). Distance between rotating parts $=15 \mathrm{~mm}$.

$\mathrm{L} 2=$ Half the width of Gear $1+15+$ Half the width of Gear $2=12.5+15+12.5=40 \mathrm{~mm}$. Therefore $\mathbf{L} \mathbf{2}=\mathbf{4 0} \mathbf{~ m m}$.

For calculating the total moment, Horizontal and Vertical Moments are required. Horizontal Moment can be calculated as follows:

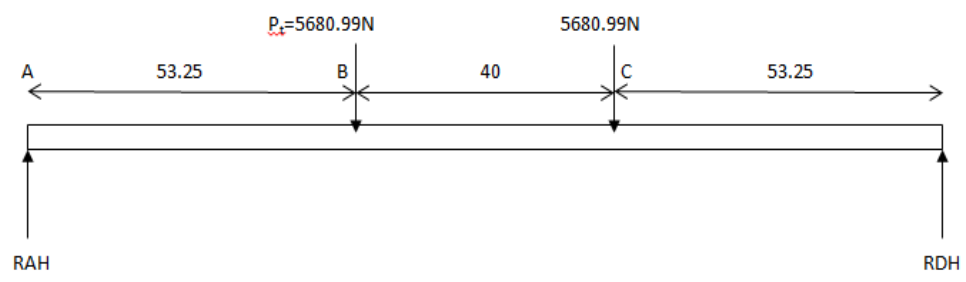

Fig:- Horizontal Moment Diagram

$\Sigma \mathrm{F}_{\mathrm{y}}=0$

Figure 5. Horizontal Moment Diagram

$\mathrm{RAH}-5680.99-5680.99+\mathrm{RDH}=0$

$\mathrm{RAH}+\mathrm{RDH}=11361.98$

$\Sigma \mathrm{Ma}=0$

Therefore, $(5680.99 \times 50.5)+(5680.99 \times 90.5)-(\mathrm{RDH} \times 141)=0$

$\mathrm{RDH}=5680.99 \mathrm{~N}$ and $\mathrm{RAH}=5680.99 \mathrm{~N}$.

Bending Moment Calculations:

At $\mathrm{A}=0$

At B $=5680.99 \times 50.5=286889.99$

At $\mathrm{C}=(5680.99 \times 90.5)-(5680.99 \times 40)=286889.99$

At $\mathrm{D}=0$.

Vertical Moment can be calculated as follows:

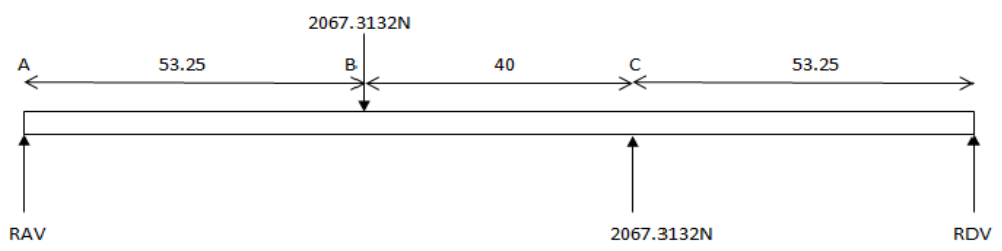

Fig:- Vertical Moment Diagram

Figure 6. Vertical Moment Diagram

$\Sigma \mathrm{F}_{\mathrm{y}}=0$

$\mathrm{RAV}-2067.31+2067.31+\mathrm{RDV}=0$

$\mathrm{RAV}+\mathrm{TDV}=0$

$\Sigma \mathrm{Ma}=0$

$(2067.31 \times 50.5)-(2067.31 \times 90.5)-(R D V \times 141)=82692.4$

$\mathrm{RDV}=-568.470 \mathrm{~N}$

$\mathrm{RAV}=568.470 \mathrm{~N}$

Bending Moment Calculations

At $\mathrm{A}=0$

At $\mathrm{B}=(568.470 \times 50.5)=29616.78$

At $C=(568.470 \times 90.5)-(2067.31 \times 40)=-31245.86$ 
At $\mathrm{D}=0$

Resultant at B

$\mathrm{Mb}=\sqrt{(286889.99)^{2}+29616.78^{2}}=\mathbf{2 8 8 4 1 4 . 6 6}$

$\mathrm{Mc}=\sqrt{(286889.99)^{2}+(-31245.86)^{2}}=\mathbf{2 8 8 5 5 8 6 . 5 0}$

$\mathrm{Te}=\sqrt{(1.5 \times 288414.66)^{2}+(1.0 \times 120.76)^{2}}=\mathbf{4 3 2 6 2 2 . 0 0}$

Now substituting the values of Moment and Torque in the equation and calculating the diameter of shaft.

$\tau_{\max }=105$

$\tau_{\max }=\frac{16}{\pi d^{3}} \times 432622$

$\mathrm{d}=26.52 \approx 28 \mathrm{~mm}$.

The value $28 \mathrm{~mm}$ is selected from the standard diameter table. Therefore Diameter of shaft is $\mathbf{2 8} \mathbf{~ m m}$.

\subsection{Design of Rack and Pinion [1]}

1) Beam Strength of gear tooth (Lewis Equation ) is given by,

$$
\boldsymbol{S} \boldsymbol{b}=\boldsymbol{m} \times \boldsymbol{b} \times \boldsymbol{\sigma} \boldsymbol{b} \times \boldsymbol{Y}
$$

In order to avoid the breakage of gear tooth due to bending, the beam strength should be more than the effective force between the meshing teeth. Therefore,

$9989.08=2.5 \times 2.5 \times 10 \times \sigma b \times 0.302$

$$
S b \geq P e f f
$$

$\sigma b=529.227 \mathrm{~N}$.

Substituting the value of $\sigma \mathrm{b}$ in the equation and calculating the beam strength.

$$
S b=2.5 \times 10 \times 2.5 \times 529.227 \times 0.302=9989.02 \mathrm{~N}
$$

The beam strength is $\mathbf{9 9 8 9 . 0 2} \mathbf{~ N}$.

2) Wear Strength of gear tooth by Buckingham's equation is given by,

$$
\begin{aligned}
Q & =\frac{2 z g}{z g+z p} \\
& =2(51) /(17+51) \\
\mathrm{Q} & =1.5 \\
\mathrm{dp} & =\mathrm{m} \times \mathrm{zp}=42.5
\end{aligned}
$$

$$
S w=b \times d p \times Q \times K
$$

Substituting the values in the equation of wear strength and calculating the value of load - stress factor (K),

$9989.08=2.5 \times 10 \times 1.5 \times 17 \times 2.5 \times K$

$\mathrm{K}=6.26 \mathrm{Mpa}$.

The load - stress factor $(\mathrm{K})$ is given by,

$$
K=0.16\left[\frac{B H N}{100}\right]^{2}
$$

Substituting the value of load - stress factor in the above equation and calculating the value of surface hardness of gears (Brinellhardness number).

$$
\begin{gathered}
6.26=0.16\left[\frac{B H N}{100}\right]^{2} \\
\boldsymbol{B H N}=\mathbf{6 2 6}
\end{gathered}
$$

Hence, depending upon the value of surface hardness of the gears, $40 \mathrm{C} 8$ with $0.20 \%$ Carbon Steel material is selected for Rack and pinion.

Calculation for Length of Rack:

Stroke Length of Shock Absorber is generally taken as 2.91 inches $=76.2 \mathrm{~mm}$

With the general considerations the length of rack can be calculated as follows:

$\mathrm{L}=$ Length of Stroke + Clearances

$=76.2+15$

$=91.2 \mathrm{~mm}$. Therefore the length of rack is given by $96.2 \mathrm{~mm}$.

\subsection{Selection of Bearing: [1]}

Input Data:

Radial Force $(\mathrm{Fr})=2067.3132 \mathrm{~N}$ (ShaftCalculations)

Diameter of Shaft $=28 \mathrm{~mm}$

Input Speed $(\mathrm{N})=548 \mathrm{RPM} \quad($ Spur Gear Calculations $)$

Expected life of bearing $=10,000$ hours $=\mathrm{L} 10 \mathrm{~h}$ 
Type: Single - row deep groove ball bearings.

Since considering only the radial load, Therefore $\mathrm{P}=\mathrm{Fr}=2067.3132 \mathrm{~N}$.

The Load life equation is given by,

But for ball bearings, $\mathrm{P}=3$

$$
L 10=\left(\frac{C}{P}\right)^{P}=\frac{60 \times N \times L 10 h}{10^{6}}
$$

L10 $=328.8$ million revolutions.

$$
L 10=\frac{60 \times 548 \times 10000}{10^{6}}
$$

$\mathrm{C}=14265.9155 \mathrm{~N}$

$$
\begin{gathered}
C=P(L 10)^{\frac{1}{3}} \\
=2067.3132 \times(328.8)^{\frac{1}{3}}
\end{gathered}
$$

\subsection{Design of Bolt: [1]}

Input Data:

Bolt Material $=30 \mathrm{C} 8$ Plain Carbon steel

Tensile Strength for Bolt Material (Syt) $=400 \mathrm{~N} / \mathrm{mm}^{2}$

From the figure the length is given by,

$\mathrm{L}=50.5+40+50.5=141 \mathrm{~mm}$.

Eccentricity e $=60 \mathrm{~mm}$.

Calculations:

The permissible shear stress is given by

Permissible Shear Stress:

$$
\begin{aligned}
& =\frac{S s y}{F O S} \\
& =\frac{0.5 \times 400}{2.5} \\
\boldsymbol{\tau} & =\mathbf{8 0 ~ N} / \mathbf{m m}^{2} \\
P 1^{\prime}=P 2^{\prime}=P 3^{\prime}= & P 4^{\prime}=\frac{P}{\text { Numberofbolts }}=\frac{P}{4} \\
= & \frac{5680.99}{4} \\
= & \mathbf{1 4 2 0 . 2 4 N}
\end{aligned}
$$

$\mathrm{P}$ x e $=P 1^{\prime \prime} r 1+P 2^{\prime \prime} r 2+P 3^{\prime \prime} r 3+P 4^{\prime \prime} r 4$

$$
\begin{aligned}
& P 1 "=c r 1 \\
& P 2 "=\operatorname{cr} 2 \\
& P 3 "=c r 3 \\
& P 4 "=c r 4 \\
& C=\frac{P e}{r 1^{2}+r 2^{2}+r 3^{2}+r 4^{2}}
\end{aligned}
$$

Due to summary,

$\mathrm{r} 1=\mathrm{r} 2=\mathrm{r} 3=\mathrm{r} 4$

$\sqrt{(80)^{2}+(70.5)^{2}}=193.31$

Similarly, $P 2 "=\mathrm{P} 3 "=\mathrm{P} 4 "=958.78$

$$
\begin{gathered}
C=\frac{5680.99 \times 130.5}{149475.02} \\
C=4.95 \\
P 1^{\prime \prime}=\frac{5680.99 \times 130.5 \times 193.31}{149475.02}=\mathbf{9 5 8 . 7 8}
\end{gathered}
$$

From figure, 


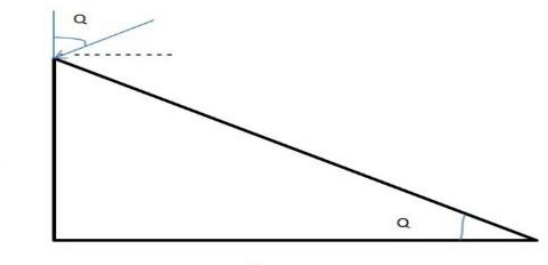

Figure 7. Forces acting on bolt.

$$
\begin{gathered}
\tan \theta=\frac{180}{70.5}=\mathbf{6 8 . 5 8}^{\circ} \\
\mathrm{P} 1=1393.46 \mathrm{~N} \\
P 1=\sqrt{(958.78 \cos 68.58-1420.24)^{2}+(958.78 \sin 168.58)^{2}} \\
\mathrm{P} 2=1982.65 \mathrm{~N}
\end{gathered}
$$

Bolts 2 and 4 are subjected to maximum shear forces.

Size of Bolts:

In the calculations of size of bolt, Critical Diameter (dc) of the bolt is calculated.

$$
\begin{gathered}
\tau=\frac{P 2}{A} \\
\tau=\frac{1982.85}{\frac{\pi}{4} \times d c^{2}}
\end{gathered}
$$

Now calculating the value of dc from the above relation by substituting all the values. Therefore,

Therefore, $\mathrm{dc}=5.61 \mathrm{~mm}$

$$
\begin{gathered}
80=\frac{1982.85}{\frac{\pi}{4} \times d c^{2}} \\
d c^{2}=31.55
\end{gathered}
$$

The actual diameter of bolt is calculated by the following relation.

$\mathrm{d}=7.02 \approx 8 \mathrm{~mm}$.

$$
d=\frac{d c}{0.8}=\frac{5.61}{0.8}
$$

Therefore M8 Bolt is selected

\section{CAD Model}

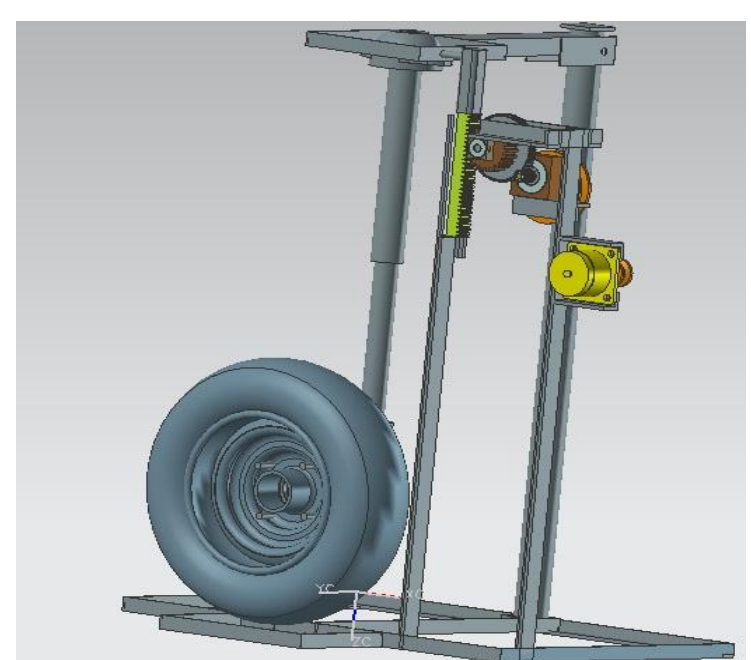

Figure 8. CAD Model 


\subsection{Calculations:}

\section{Result}

The calculations are based upon the amplitude of vibration. So depending upon the total amplitude of vibration we consider an amplitude of $50 \mathrm{~mm}$.

Power is calculated for the given amplitude.

Torque $\mathrm{T}$ is given by, $\mathbf{T}=\mathbf{F} \mathbf{x} \mathbf{R}$

The power can be calculated by including the Torque and Force by the relation, $\mathbf{P}=\mathbf{2 \pi} \boldsymbol{N T} / \mathbf{6 0}$

\subsection{Result Table:}

\begin{tabular}{|c|c|c|c|c|c|}
\hline SR NO & AMPLITUDE (MM) & $\boldsymbol{x}$ & $\dot{\boldsymbol{x}}$ & $\ddot{x}$ & POWER (W) \\
\hline 1 & $\mathbf{5 0}$ & $\mathbf{0 . 0 5 0}$ & $\mathbf{0 . 0 9 9}$ & $\mathbf{0 . 0 1 1}$ & $\mathbf{0 . 5 0}$ \\
\hline 2 & $\mathbf{2 5}$ & $\mathbf{0 . 0 2 5}$ & $\mathbf{0 . 0 4 9}$ & $\mathbf{0 . 0 0 5}$ & $\mathbf{0 . 2 5}$ \\
\hline 3 & $\mathbf{7 0}$ & $\mathbf{0 . 0 7 0}$ & $\mathbf{0 . 0 1 3}$ & $\mathbf{0 . 0 1 5}$ & $\mathbf{0 . 7 0}$ \\
\hline
\end{tabular}

\section{Power extracted on 4 wheels:}

1. Quarter deflection $(25 \mathrm{~mm})=0.25 \times 4=1 \mathrm{~W}$

2. Semi deflection $(50 \mathrm{~mm})=0.50 \times 4=2 \mathrm{~W}$

3. Full deflection $(70 \mathrm{~mm})=0.70 \times 4=2.8 \mathrm{~W}$

\section{Prototype}

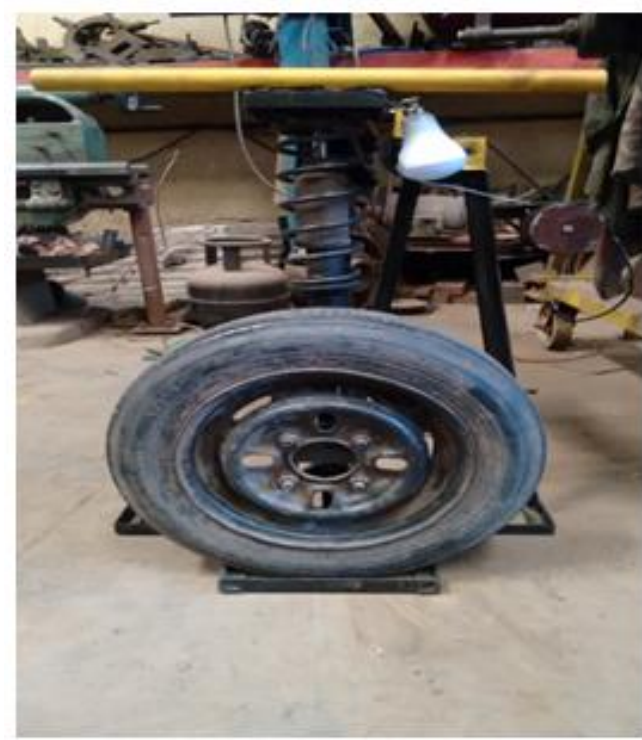

Figure 9. Prototype

\section{Conclusion}

On the basis of test result we found that the total power extracted per buffer is 2 watts. An effort has been made to develop the mechanism, successful trial has been conducted and the test model has been checked for locking and functional and found well in operation. With this project we got an idea regarding mechanism synthesis design and development design concept. Future modifications can be made in material to make the project more efficient.

\section{References}

[1]. V.B.Bhandari, "Design of Machine Elements", Tata McGraw Hill publications

[2]. W. T. Thompson, "Theory of Vibration",CRC Press, 01-Feb-1996

[3]. Zhang Jin-qiu, Peng Zhi-zhao, Zhang Lei, Zhang Yu, "A Review on Energy-Regenerative Suspension Systems for Vehicles", Proceedings of the World Congress on Engineering 2013 Vol III, WCE 2013,July 3 - 5, 2013, London, U.K.

[4]. Steven A. Velinsky, Robert A. White, "Vehicle Energy Dissipation Due to Road Roughness".

[5]. Sethu Prakash S, Nidhin Abraham Mammen, Steve John, Varughese Punnoose Kochuparackal, Tobin Thomas. "Regenerative Shock Absorber", International Journal of Science, Technology \& Management, Volume No 04, Special Issue No. 01 , March 2015

[6]. Mukti Nath Gupta, Suman and S.K. Yadav."Electricity Generation Due to Vibration of Moving Vehicles Using Piezoelectric Effect"Advance in Electronic and Electric Engineering.ISSN 2231-1297, Volume4, Number 3(2014), pp.313-318 